\title{
TESTE DA LIBIDO EM TOUROS JOVENS GUZERÁ E SUAS ASSOCIAÇÕES COM CARACTERÍSTICAS REPRODUTIVAS E NÍVEIS SÉRICOS DE TESTOSTERONA
}

\section{Libido test in young Guzerat bulls and their associations with reproductive traits and serum testosterone levels}

\author{
DIAS, J.C. ${ }^{1}$; ANDRADE, V.J. ${ }^{1}$; EMERICK, L.L. ${ }^{1}$; MARTINS, J.A.M. ${ }^{1}$; \\ VALE FILHO, V.R. ${ }^{1}$; SILVA, M.A. ${ }^{1}$ \\ ${ }^{1}$ Escola de Veterinária da Universidade Federal de Minas Gerais, Belo Horizonte/MG.
}

Endereço para correspondência: Juliano Cesar Dias: julianocdias@yahoo.com.br

\section{RESUMO}

Um total de 12 touros da raça Guzerá, de 24 a 34 meses de idade, avaliados andrologicamente, foram submetidos a teste da libido com o objetivo de estudar 0 comportamento sexual em curral, por 5, 10 e 15 minutos de observação; e associar com características andrológicas (aspectos físicos: motilidade, vigor, turbilhonamento e concentração espermática, e volume do sêmen; e morfológicos: defeitos espermáticos maiores, menores e totais, do sêmen), circunferência escrotal (CE), classificação andrológica por pontos (CAP), peso corporal, idade e concentrações séricas de testosterona. Observou-se, de forma geral, baixa resposta dos animais aos testes, uma vez que menos da metade dos animais foi classificada com libido média ou alta. Verificouse pequena variação na pontuação entre os tempos de observação, com escore 3,0 em 5 minutos e 3,3 em 15 minutos de avaliação $(P>0,05)$. A associação entre a libido e as concentrações séricas de testosterona $(0,78)$ reforça o achado de influência desta característica na expressão do interesse sexual em touros jovens Guzerá.

Palavras-chave: comportamento sexual; Guzerá; libido; testosterona; zebu

\section{ABSTRACT}

Twelve Guzerat bulls from 24 to 34 months age old, andrologically evaluated as normal were submitted to a libido test, were used to study sexual behavior in pen, during observations periods of 5, 10 and 15 minutes and associate with andrologic traits (physic and morphologic aspects of semen), scrotal circumference, breeding soundness evaluation for Zebu, body weight, age and serum testosterone concentrations. It was observed, in a general way, low reply of the animals to the tests, once that less than half of them were classified with average or high libido. Lower variation in the punctuation between the observation times was verified, with score 3.0 in 5 minutes and 3.3 in 15 minutes of evaluation $(P>0.05)$. The association between libido and serum testosterone concentrations (0.78) strengthens the finding of direct influence of these characteristics in the expression of sexual interest in young Guzerat bulls.

Key words: Guzerat; libido; sexual behavior; testosterone; zebu 


\section{INTRODUÇÃO}

O comportamento sexual do touro, que sabidamente exerce importante influência na fertilidade do rebanho, tem sido avaliado pela intensidade da libido (Hultnãs, 1959), da capacidade de serviço (Rupp et al., 1977; Chenoweth et al., 1984) e do comportamento sexual a campo (Zuin, 2000; Santos, 2001). A libido é o momento em que o macho demonstra o interesse sexual, podendo ser caracterizado como a espontaneidade ou avidez para montar e a habilidade de completar o serviço em uma fêmea (Hultnãs, 1959).

Comparando-se os testes de libido, capacidade de serviço e tempo de reação para primeiro serviço em touros de corte jovens, Chenoweth et al. (1979) concluíram que o teste da libido apresenta vantagens por avaliar e refletir melhor 0 comportamento destes animais. Os autores ressaltaram ainda o fato do teste de libido tratar de uma avaliação de menor duração e maior praticidade que o teste de capacidade de serviço.

Apesar dos esforços de pesquisadores brasileiros (Pinto et al., 1989; Vale Filho et al., 1994), ainda existem muitas dúvidas com relação aos critérios de execução dos testes de avaliação do comportamento sexual dos zebuínos e do real potencial reprodutivo da espécie em condições extensivas de criação. Tem sido demonstrado que touros que apresentam altas classificações quanto à libido, capacidade de serviço e de razoáveis a altas pontuações nos sistemas de classificação andrológica, podem servir a maior número de fêmeas durante a estação de monta, possibilitando assim maior pressão de seleção (Fonseca et al., 1997; Salvador et al., 2003), aliado à redução dos custos com os mesmos (Neville Jr. et al., 1988; Fonseca, 2000).

O objetivo deste estudo foi avaliar o comportamento sexual de touros jovens Guzerá, sem experiência sexual, e associá-lo com características reprodutivas, níveis séricos de testosterona e peso corporal.

\section{MATERIAL E MÉTODOS}

O trabalho foi desenvolvido em junho de 2006, na Fazenda Palestina, de propriedade da Palestina Agropastoril Ltda., município de Unaí, noroeste do estado de Minas Gerais, tendo como coordenadas geográficas $16^{\circ} 35^{\prime} S$ de latitude e $46^{\circ} 47^{\prime} \mathrm{W}$ de longitude, situada em área de Cerrado. A região apresenta clima descrito como quente e úmido tipo AW de Köeppen, com temperaturas máxima e mínima de 30,8 e $17,2{ }^{\circ} \mathrm{C}$, respectivamente, com precipitação pluviométrica média anual de $1437 \mathrm{~mm}$. Dois períodos climáticos são observados, o seco que se estende de abril a setembro e o chuvoso de outubro a março.

Foram inicialmente examinados, andrologicamente, um total de 12 touros com idades variando de 24 a 34 meses, sem experiência sexual prévia. Avaliaramse os aspectos clínico-andrológicos, circunferência escrotal (CE) e biometria testicular (comprimento e largura), além dos aspectos físicos e morfológicos do sêmen, conforme recomendação do Colégio Brasileiro de Reprodução Animal (1998), sendo então os animais submetidos à classificação andrológica por pontos (CAP), segundo (Vale Filho, 1989).

O esquema de teste da libido utilizado foi o proposto por Vale Filho et al. (1994), no qual os autores sugerem que a libido seja avaliada num lote de 20 fêmeas soltas no curral, das quais três em estro. Neste teste, o animal a ser avaliado permanece em lotes de três touros, em curral adjacente ao local do teste da libido, para observação das fêmeas em cio (préestimulação coletiva); sendo posteriormente colocado individualmente em curral anexo (pré-estimulação individual). Os 
animais, após pré-estimulação coletiva e individual, foram colocados individualmente com as fêmeas, em curral com aproximadamente $225 \mathrm{~m}^{2}(15 \times 15 \mathrm{~m})$, sendo observados por 5,10 e 15 minutos sequenciais.

Os principais comportamentos padronizados para observação durante a avaliação foram os descritos por Chenoweth (1984): 0) o touro não mostrou interesse sexual pela fêmea; 1) interesse sexual mostrado apenas uma vez (ex: cheirar a região perineal); 2) positivo interesse pela fêmea em mais de uma ocasião (ex: reflexo de Flehmen); 3) ativa perseguição da fêmea com persistente interesse sexual (ex: impulso de monta); 4) uma monta ou tentativa de monta, mas nenhum serviço; 5) duas montas ou tentativas de monta, mas nenhum serviço; 6) mais de duas montas ou tentativas de monta, nenhum serviço; 7) um serviço (monta completa ou cópula) seguido por nenhum interesse sexual; 8) um serviço seguido por interesse sexual, incluindo montas ou tentativas de monta; 9) dois serviços seguidos por nenhum interesse sexual; 10) dois serviços ou mais, seguidos por interesse sexual, incluindo montas, tentativas de monta e serviços.

Para cada atitude dos touros frente às vacas foi atribuída uma pontuação, e após o término do teste da libido, foi feita a leitura complementar ou média entre as planilhas dos observadores, sendo os touros classificados em três categorias:

- Baixa libido - comportamentos 0, 1, 2 e 3; - Média libido - comportamentos 4, 5 e 6;

- Alta libido - comportamentos 7, 8, 9 e 10.

Realizou-se, ainda, a anotação de todo evento comportamental realizado pelos touros durante os testes, para a verificação da frequência de cada comportamento nos diferentes testes e diferentes tempos de observação.

Os touros foram reavaliados andrologicamente após os testes, para a tomada das características andrológicas dos animais próximo à realização dos testes; foram ainda, submetidos à coleta de sangue por punção da veia jugular, para avaliação das concentrações séricas de testosterona (Testosterona Total COATA-COUNT ${ }^{\circledR}$ - DPC - Diagnostic Products Corporation, Los Angeles, Califórnia, USA), na busca de associações entre a libido, as características andrológicas e a concentração sérica de testosterona.

As vacas utilizadas no teste foram avaliadas ginecologicamente e tiveram o estro induzido por hormonioterapia, com aplicação intramuscular de $5 \mathrm{ml}$ de cipionato de estradiol (E.C.P. ${ }^{\circledR}$ Laboratório Pfizer) e $3 \mathrm{ml}$ de prostaglandina sintética $\quad\left(\right.$ Ciosin ${ }^{\circledR}$ Laboratório Schering-Plough). As fêmeas eram substituídas constantemente, ou a cada duas montas completas, para evitar recusa a novos serviços.

Para a comparação das frequências de manifestações dos diferentes comportamentos dos touros frente às vacas e a associação entre os eventos e entre estes e diferentes características andrológicas, agrupou-se os eventos em cinco:

- Cheirar a região perineal (CRP);

- Reflexo de Flehmen (RF);

- Impulso de monta (IM);

- Tentativa de monta ou monta abortada (TM/MA);

- Monta completa (MC).

As comparações da classificação final dos animais nos diferentes tempos, assim como as frequências dos comportamentos dos touros foram feitas como análises não paramétricas usando-se 0 teste de Wilcoxon, segundo proposição de Sampaio (2002). Para a análise de comparação das frequências dos eventos, foi adotado o teste de maior duração (15 minutos), período onde ocorreu a maior manifestação dos eventos.

Para a análise das correlações entre a libido e as características andrológicas, 
Tabela 1 - Médias e desvios-padrão da idade, peso corporal, circunferência escrotal e características seminais em touros da raça Guzerá, submetidos à avaliação da libido em curral.

\begin{tabular}{cccccccccc}
\hline $\begin{array}{c}\text { Idade } \\
\text { (meses) }\end{array}$ & $\begin{array}{c}\text { Peso } \\
(\mathrm{Kg})\end{array}$ & $\begin{array}{c}\mathrm{CE} \\
(\mathrm{cm})\end{array}$ & $\begin{array}{c}\text { Mot } \\
(\%)\end{array}$ & $\begin{array}{c}\text { Vigor* } \\
(0-5)\end{array}$ & $\begin{array}{c}\mathrm{DM} \\
(\%)\end{array}$ & $\begin{array}{c}\mathrm{DT} \\
(\%)\end{array}$ & $\begin{array}{c}\text { Vol } \\
(\mathrm{ml})\end{array}$ & $\begin{array}{c}\text { Conc } \\
\left(\times 10^{6} \mathrm{sptz} / \mathrm{ml}\right)\end{array}$ & $\begin{array}{c}\mathrm{CAP}^{*} \\
(0-100)\end{array}$ \\
\hline 29,8 & 463,5 & & 58,3 & 4,2 & & 19,5 & & 284,4 & 66,5 \\
\pm & \pm & $31,9 \pm$ & \pm & \pm & $7,8 \pm$ & \pm & $9,0 \pm$ & \pm & \pm \\
3,1 & 97,4 & 2,6 & 8,3 & 0,7 & 5,2 & 6,4 & 1,4 & 102,1 & 13,8 \\
\hline
\end{tabular}

Peso = peso corporal; $C E$ = circunferência escrotal; Mot = motilidade espermática; Vigor = vigor espermático; $\mathrm{DM}=$ defeitos espermáticos maiores; $\mathrm{DT}=$ total de defeitos espermáticos; Vol = volume seminal; Conc = concentração espermática; CAP = classificação andrológica por pontos.

concentrações séricas de testosterona, CAP, peso corporal e idade dos animais, utilizou-se a correlação de Spearman, recomendada para dados não paramétricos, também segundo Sampaio (2002), com recursos do pacote estatístico SAS (1996). O escore utilizado para o cálculo foi o da pontuação máxima de cada animal no teste de maior duração.

\section{RESULTADOS}

$\mathrm{Na}$ Tabela 1 são apresentadas as médias e desvios-padrão da idade, peso corporal, CE, características físicas e morfológicas do sêmen e CAP para touros Guzerá. Os resultados encontrados foram semelhantes aos descritos para touros Guzerá por Trocóniz et al. (1991) e Torres Júnior (2004).

Apenas $16,7 \%$ dos animais foram classificados como de alta; $16,7 \%$ de média e $66,6 \%$ de baixa libido. As médias e desvios-padrão dos escores da libido foram $3,0 \pm 2,3,3,0 \pm 2,3$ e $3,3 \pm 2,3$, respectivamente, para 5,10 e 15 minutos de observação, sem diferença entre os tempos $(P>0,05)$.

A seguir serão apresentados os resultados das frequências médias dos eventos comportamentais em touros Guzerá; sendo os comportamentos de cheirar e lamber a região perineal (CRP), reflexo de Flehmen (RF), impulso de monta (IM), tentativa de monta/monta abortada (TM/MA) e monta completa (MC) descritos para touros de alta; os comportamentos CRP, RF, IM e TM/MA para os de média; e os comportamentos
CRP, RF e IM para os de baixa libido. Esses eventos de manifestação sexual podem, ainda, ser divididos em comportamentos de identificação (CRP, RF), pré-copulatórios (IM, TM/MA) e copulatórios (MC) (Santos, 2001; Torres Júnior, 2004).

$\mathrm{Na}$ Figura 1 é apresentada a frequência dos eventos de comportamento sexual, em touros da raça Guzerá, em teste da libido em curral.

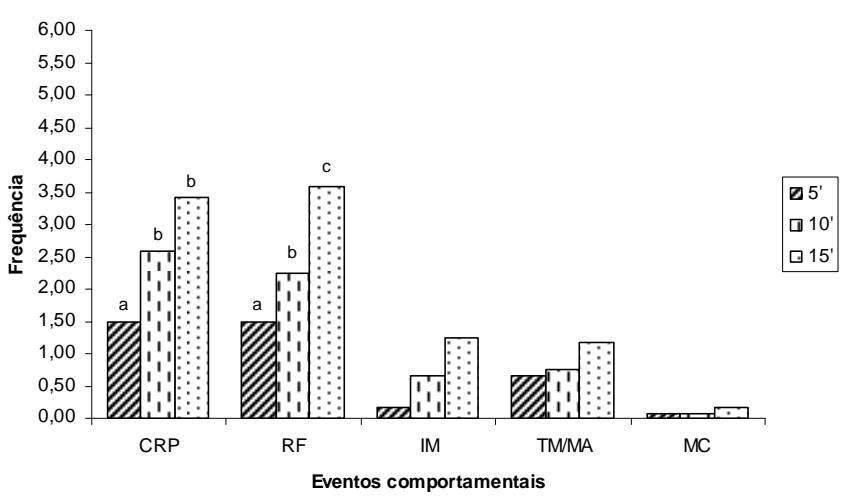

$\mathrm{CRP}=$ cheirar a região perineal; $\mathrm{RF}$ = reflexo de Flehmen; IM = impulso de monta; $\mathrm{TM} / \mathrm{MA}=$ tentativa de monta/monta abortada; MC = monta completa; $5^{\prime}=$ cinco minutos; $10^{\prime}=10$ minutos; $15^{\prime}=15$ minutos.

Figura 1 - Frequência de eventos de comportamento sexual em touros jovens da raça Guzerá em teste da libido em curral, com diferentes tempos de avaliação. OBS: Letras diferentes nas colunas diferem $(\mathrm{P}<0,05)$ pelo teste de Wilcoxon.

Observou-se que os eventos com maior frequência de manifestação foram os de identificação, principalmente os eventos CRP e RF, independentemente do tempo de avaliação. Registrou-se baixa incidência dos eventos de impulso de monta (IM) e, tentativa de monta/monta abortada (TM/MA), com incidência mínima para o evento de monta completa (MC), conforme 
Tabela 2 - Médias e desvios-padrão da frequência de eventos sexuais em touros da raça Guzerá em avaliação em curral

\begin{tabular}{cccccc}
\hline & \multicolumn{5}{c}{ Eventos Sexuais } \\
\cline { 2 - 6 } & CRP & RF & IM & TM/MA & MC \\
\hline Alta & $3,5 \pm 0,7$ & $7,5 \pm 4,9$ & $3,5 \pm 4,9$ & $2,5 \pm 0,7$ & $1,0 \pm 0,0$ \\
Média & $4,5 \pm 2,1$ & $4,0 \pm 1,4$ & $4,0 \pm 5,6$ & $4,5 \pm 4,9$ & - \\
Baixa & $3,1 \pm 3,0$ & $2,5 \pm 1,6$ & - & - & - \\
\hline
\end{tabular}

Não houve diferenças significativas $(P>0,05)$ entre as características pelos testes de Kruskal Wallis e MannWhitney.

$\mathrm{CRP}=$ cheirar a região perineal; $\mathrm{RF}=$ reflexo de Flehmen; $\mathrm{IM}=$ impulso de monta; $\mathrm{TM} / \mathrm{MA}=$ tentativa de monta/monta abortada; $\mathrm{MC}=$ monta completa.

relatado por Torres-Júnior (2004). Quando se comparou a frequência de manifestação dos eventos entre os tempos de avaliação, registrou-se diferença $(P<0,05)$ apenas nos eventos CRP e RF, com o RF aumentando juntamente com o aumento no tempo de avaliação.

Não se registrou diferença entre os eventos nos animais com alta, média e baixa libido, em avaliação em curral (Tabela 2); constatou-se que os eventos indicativos de interesse sexual ou reconhecimento da fêmea em estro foram manifestados por um maior número de animais, independente de sua classifica-ção final.

Tabela 3 - Correlações de Spearman entre a libido e idade, peso corporal, características andrológicas, classificação andrológica por pontos e concentração sérica de testosterona em touros da raça Guzerá.

Individual (valor de $\mathrm{P}$ )

Idade (meses)

Peso corporal (kg)

Circunferência escrotal $(\mathrm{cm})$

$0,41(0,1676)$

$0,55(0,0652)$

$0,31(0,2993)$

Consistência testicular (1-5)

$0,44(0,1440)$

Motilidade espermática (\%)

$0,34(0,2509)$

Vigor espermático (0-5)

$0,16(0,5778)$

Turbilhonamento espermático (0-5)

$0,24(0,4203)$

Volume do sêmen (ml)

$0,26(0,3844)$

Concentração espermática (sptz/ml)

$0,50(0,1505)$

Defeitos espermáticos maiores (\%)

$-0,24(0,4270)$

Defeitos espermáticos menores (\%)

$0,12(0,6806)$

Total de defeitos espermáticos (\%)

$-0,24(0,4236)$

Classificação andrológica por

pontos (0-100)

$0,46(0,1258)$

Testosterona (ng/ml)

$0,78(0,0097)$
$\mathrm{Na}$ Tabela 3 encontram-se correlações simples entre a libido e idade, peso corporal, características andrológicas, CAP e concentrações séricas de testosterona em touros da raça Guzerá.

Encontraram-se associações favoráveis entre libido e concentrações séricas de testosterona $(0,78)$. Não foram encontradas associações favoráveis entre a libido e idade, peso corporal, circunferência escrotal e características físicas e morfológicas do sêmen; reforçando os achados de Salvador et al. (2003) de que a libido deve ser um teste complementar ao exame andrológico na avaliação de touros para alto desempenho reprodutivo.

\section{DISCUSSÃO}

Observou-se, de forma geral, baixa resposta dos animais aos testes, uma vez que menos da metade dos animais foi classificada com libido média ou alta. Os resultados foram semelhantes aos encontrados por Jiménez-Severiano (2002), que reportaram menos de $20 \%$ de montas completas em machos das raças Holandês e Pardo-Suiço, com idades variando de seis a 16 meses.

Fonseca et al. (1997), avaliando touros adultos da raça Nelore por 10 minutos, observaram resultados semelhantes, com 50,8; 45,6; 3,6 e 0,0\%, de animais classificados como questionáveis, bons, muito bons e excelentes, respectivamente. Já Santos et al. (2004) observaram, em teste de libido por 10 e 15 minutos, também com animais adultos, 32,1; 42,9; 21,4 e 3,6\%, e 26,8 ; 
25,$0 ; 42,8$ e 5,4\%, respectivamente, utilizando o mesmo critério de classificação descrito anteriormente. Os autores alegaram que o aumento no tempo de avaliação de 10 para 15 minutos reduziu o percentual de touros classificados como de boa ou questionável libido e elevou o de touros com libido muito boa e excelente.

Os resultados obtidos nos testes mostram inibição dos animais na manifestação dos eventos comportamentais e sugerem que tais resultados devemse, provavelmente, à baixa idade, aliada a inexperiência sexual dos animais avaliados. Segundo Hafez (1995), a eficiência da cópula de machos e fêmeas é melhorada pela experiência e contatos individuais antes da puberdade podem proporcionar um efeito organizador sobre o desempenho sexual subsequente. Desta forma, variações quanto à classificação da libido poderiam existir em função da inexperiência sexual, quando comparados aos animais mais velhos (Phillips, 1993, citado por Quirino et al., 2004).

Chenoweth et al. (1979) encontraram em touros jovens Bos taurus taurus, em teste da libido por 10 minutos, pontuação média de 5,7 e sugeriram que embora a pontuação no teste possa ser um método útil de avaliação da conduta sexual dos animais, isso não quer dizer que seja o método mais adequado. Avaliando o comportamento sexual de touros Nelore adultos, Pineda et al. (1997) observaram pontuação média de 4,5 em avaliação por 10 minutos, semelhante ao descrito por Santos et al. (2004) utilizando touros da mesma raça e mesmo tempo de avaliação. Entretanto, Santos et al. (2004) encontraram diferença na pontuação de touros Nelore adultos ao estudarem diferentes tempos de avaliação, sugerindo que o tempo de 10 minutos poderia interferir negativamente no desempenho sexual dos touros, quando comparado a avaliação por 15 minutos (4,5 vs 5,5$)$; fato também constatado por Oliveira et al. (2007) que questionaram o tempo de avaliação de 10 minutos em curral, sugerindo ser insuficiente para expressão do potencial sexual dos animais. Tais resultados reforçam a importância da avaliação clínica dos órgãos genitais e análise do sêmen na seleção andrológica dos reprodutores, mostrando ser a libido um teste complementar importantíssimo no sentido de aumentar a segurança na avaliação do potencial reprodutivo dos touros para uso com maiores proporções touro:vaca, durante a estação de monta, conforme sugerido por Salvador et al. (2003).

Os resultados apresentados indicam que machos jovens da raça Guzerá, sem experiência sexual prévia, podem manifestar interesse sexual por fêmeas em estro, em teste da libido. Apesar da menor frequência na manifestação dos eventos, quando comparados com Bos taurus taurus (Chenoweth et al., 1979; Neville Jr. et al., 1988) e com Bos taurus indicus, em idades mais avançadas e experientes sexualmente (Salvador et al., 2003; Santos et al., 2004), pode-se constatar certa eficiência nos testes na detecção de animais com maiores potenciais de cobrição.

Crudeli (1990) sugeriu que o teste da libido não está perfeitamente adequado ao temperamento do zebuíno, bastante nervoso e sensível ao estresse em ambiente diferente ao que se encontra acostumado. Silva (1994) enfatizou que o touro zebu comporta-se com restrições em currais fechados; entretanto destacou que a tentativa de realizar estes testes em ambiente mais natural como piquetes, resultou em fracasso, principalmente por problemas relacionados às fêmeas.

A utilização de fêmeas em estro, juntamente com as fora de estro, durante a realização dos testes foi importante para comprovar que os machos foram atraídos às fêmeas em estro, concentrando os eventos sexuais, quase em sua totalidade, sobre estas; semelhante ao descrito na literatura para avaliação em zebuínos 
(Silva, 1994; Torres Júnior, 2004); indicando que o estado reprodutivo da fêmea foi determinante como estímulo ao comportamento sexual do touro (Santos, 2001).

Observou-se que os eventos classificados como de identificação foram os com maior incidência neste trabalho, com os eventos de cheirar e lamber a região perineal (CRP) e reflexo de Flehmen (RF), com maior ocorrência, mostrando a importância de tais eventos na manifestação do desejo sexual nesses animais, fato também reportado por outros pesquisadores (Costa e Silva et al., 1999; Salvador et al., 2003).

Silva (1994) levantou a questão dos valores atribuídos a cada atitude do comportamento sexual, onde as mais importantes são os serviços completos, seguidos das tentativas de monta e montas; entretanto citou fatos que contradizem a valorização destas atitudes na subespécie zebuína, onde o cortejo é mais demorado e envolvente, resultando em menor número de montas, conforme observado neste estudo.

Salvador (2001), ao estudar o comportamento sexual de touros Nelore adultos, observou que touros de alta libido foram mais diretos ou mais rápidos na realização dos comportamentos copulatórios, com menor frequência de RF que os touros classificados como de baixa libido, fato não observado neste estudo. $\mathrm{O}$ autor sugeriu ainda que touros com comportamentos mais diretos durante os testes da libido em curral, podem também ser os de maior dominância a campo, semelhante ao descrito por Costa e Silva (2002) ao observar que, em touros Nelore, em acasalamentos múltiplos, o estabelecimento da relação de dominância, determinava que os subordinados praticavam com maior frequência os comportamentos de identificação de fêmeas no cio e os dominantes mostravam-se mais rápidos em atingir os eventos copulatórios.
O impulso de monta (IM), evento caracterizado como um leve e súbito movimento do touro em direção a fêmea, com a retirada ou não dos membros torácicos do solo, sem apoio sobre a fêmea; e a tentativa de monta/monta abortada (TM/MA), foram eventos com ocorrência semelhante neste trabalho, diferente do registrado por vários outros pesquisadores (Costa e Silva, 2002; Torres Júnior, 2004). Estes autores encontraram maior ocorrência de IM, alegando que este evento está associado a uma forma de excitação, assim como, a uma forma de identificar a receptividade da fêmea e eventual melhor momento para realização da cópula. Já Santos (2001), caracteriza a TM/MA como evento pouco expressivo para expressar o comportamento de touros zebuínos, diferentemente do exposto por Chenoweth (1984) para touros taurinos.

O comportamento de MC foi o evento de menor ocorrência nos sistemas de avaliação utilizados, com frequência de 0 a $16,6 \%$ entre os animais avaliados. Chenoweth et al. (1996), também trabalhando com machos zebuínos (Brahman e Nelore x Brahman), de até 20 meses de idade, não reportaram a ocorrência de montas completas, em teste com 10 minutos de duração, porém utilizando fêmeas contidas e sem manifestação do estro.

Os resultados sugerem que os eventos de identificação deveriam ser mais bem pontuados durante a realização dos testes utilizados na avaliação do comportamento sexual de zebuínos, principalmente em touros jovens e sem experiência sexual; devendo levar em consideração o comportamento adaptativo, típico desta subespécie. Mader e Price (1984) citaram que, em situação de acasalamento natural, comportamentos sexuais que não culminem com serviço completo não necessariamente representam desperdício de tempo e energia. 
Costa e Silva (2002) sugeriram revisão nos métodos dos testes comportamentais, indicando adequação dos mesmos de forma a privilegiar eventos importantes para o sucesso reprodutivo dos touros a campo. Sugeriram, ainda, mais estudos para confirmar a hipótese de que comportamentos como CRP e IM, importantes na determinação da cópula em touros Nelore, têm componentes adaptativos e se são herdáveis, com possibilidade de seleção. Para Chenoweth (1983), o comportamento sexual está sujeito a uma série de influências que vão desde fatores genéticos, ambientais e hormonais, até mesmo a ordem de dominância social do indivíduo no grupo.

Dentre os fatores citados anteriormente, os fatores hormonais tem influência direta na condição reprodutiva do macho. Segundo Senger (2003), os andrógenos são essenciais à função reprodutiva destes animais por atuar na manutenção das características sexuais secundárias e no comportamento sexual. Tais afirmações reforçam os achados deste estudo, onde a associação favorável entre a libido e a concentração sérica de testosterona indica influência direta deste hormônio na manifestação do comportamento sexual dos animais.

Alguns trabalhos têm sugerido que, em machos adultos mamíferos, o controle endócrino do comportamento sexual é feito pela testosterona, entretanto evidências indicam que estrógeno e diidrotestosterona também participam da função erétil e do comportamento sexual em algumas espécies (Henney et al., 1990; Parvizi, 2000; Pinckard et al., 2000).

Henney et al. (1990) descreveram que a testosterona, após ser sintetizada nos testículos liga-se à área pré-óptica do hipotálamo onde é convertida em estradiol pela enzima aromatase, com o estradiol afetando positivamente o comportamento sexual masculino. Hormônios androgênios estimulam a atividade da enzima aromatase e, maiores níveis circulantes de testosterona, disponíveis para aromatização no cérebro, afetam a libido.

Foot et al. (1976) alegaram que se a associação entre a libido e a testosterona existir dentro de uma população de touros, resultados adversos podem ser provenientes de variações no complexo globulina-testosterona, nos receptores hormonais ou na inabilidade do tecido neural alvo em converter a testosterona circulante para uma forma mais ativa. Entretanto, em bovinos, a testosterona não tem sido associada a diferenças na libido (Santos et al., 2000), sugerindo que a concentração para manter o comportamento sexual masculino seja menor que a capacidade secretora dos testículos, fato não confirmado neste estudo.

\section{CONCLUSÕES}

A avaliação do comportamento sexual, em teste da libido, por 5, 10 e 15 minutos se mostrou eficiente na manifestação do desejo sexual, sendo uma avaliação complementar ao exame andrológico na determinação do potencial reprodutivo de touros. Alterações nas concentrações circulantes de testosterona podem ser responsáveis por diferenças na manifestação do comportamento sexual em touros jovens Guzerá.

\section{REFERÊNCIAS}

BLOCKEY, M.A.B. The influence of serving capacity of bulls on herd fertility. Journal of Animal Science, v.46, p.589-595, 1978.

BLOCKEY, M.A.B. Development of a serving capacity test for beef bulls. Applied Animal Ethology, v.7, p.307-319, 1981.

CHENOWETH, P.J.; BRINKS, J.S.; NETT, T.M. A comparison of three methods of assessing sex-drive in yearling beef bulls and relationships with testosterone and LH levels. Theriogenology, v.12, p.223-233, 1979.

CHENOWETH, P.J. Sexual behavior of the bull: a review. Journal of Dairy Science, v.66, p.173-179, 1983. 
CHENOWETH, P.J. Examination of bulls for libido and breeding ability. Veterinary Clinics of North America: Animal Practice, v.5, p.59-74, 1984.

CHENOWETH, P.J.; FARIN, P.W.; MATEOS, E.R. et al. Breeding soundness and sex drive by breed and age in beef bulls used for natural mating.

Theriogenology, v.22, p.341-349, p. 1984.

CHENOWETH, P.J.; CHASE JR, C.C.; LARSEN, R.E. et al. The assessment of sexual performance in young Bos taurus and Bos indicus beef bulls.

Applied Animal Behaviour Science, v.48, p.225235, 1996.

COLÉGIO BRASILEIRO DE REPRODUÇÃO ANIMAL - CBRA. Manual para exame andrológico e avaliação de sêmen animal. 2.ed. Belo Horizonte: CBRA, 1998. 49p.

COSTA E SILVA, E.V.; SERENO, J.R.B.; PARANHOS DA COSTA, M.J.R. et al. Frequência de montas por touros Nelore (Bos taurus indicus) em sistema de acasalamento múltiplo: efeito da hierarquia. In: ENCONTRO ANUAL DE ETOLOGIA, 16, 1998, São José do Rio Preto. Anais... São José do Rio Preto: SBEt, 1998. p.48.

COSTA E SILVA, E.V.; SERENO, J.R.B.; PARANHOS DA COSTA, M.J.R. et al. Comportamento sexual de touros Nelore (Bos taurus indicus) e pantaneiro (Bos taurus taurus) durante os procedimentos de teste de libido.

Revista Brasileira de Reprodução Animal, v.23, p.214-216, 1999.

COSTA E SILVA, E.V. Comportamento sexual de touros Nelore (Bos taurus indicus) em monta a campo e em teste de libido. 2002. 137p. Tese (Doutorado em Zootecnia) - Faculdade de Ciências Agrárias e Veterinárias. Universidade Estadual Paulista, Jaboticabal.

CRUDELI, G.A. Avaliação da aptidão reprodutiva de touros da raça Nelore e seu efeito sobre a taxa de gestação do rebanho. 1990. 135p. Dissertação (Mestrado em Medicina Veterinária) Escola de Veterinária, Universidade Federal de Minas Gerais, Belo Horizonte.

FONSECA, V.O.; FRANCO, C.S.; BERGMANN, J.A.G. et al. Potencial reprodutivo de touros da raça Nelore (Bos taurus indicus) acasalados com elevado número de vacas. Arquivo Brasileiro de Medicina Veterinária e Zootecnia, v.49, p.53-62, 1997.

FONSECA, V.O. O touro no contexto da eficiência reprodutiva do rebanho. Informe Agropecuário, v.21, p.48-63, 2000.

FOOT, R.H.; MUNKENBECK, N.; GREENE, A. Testosterone and libido in Holstein bulls of various ages. Journal of Dairy Science, v.59, p.20112013, 1976.

HAFEZ, E.S.E. Reprodução animal. 6.ed. São Paulo: Manole Ltda, 1995. 582p.

HENNEY, S.R.; KILLIAN, G.J.; DEAVER, D.R. Libido, hormone concentrations in blood plasma and semen characteristics in Holstein bulls. Journal of Animal Science, v.68, p.2784-2792, 1990.

HULTNÃS, C.A. Studies on variation in mating behavior and semen picture in young bulls of the Swedish red and white breed and on causes of this variation. Acta Agriculturae Scandinavica, v.9, p.1-82, 1959.

JIMÉNEZ-SEVERIANO, H. Sexual development of dairy bulls in the Mexican tropics. Theriogenology, v.58, p.921-932, 2002.

MADER, D.R.; PRICE, E.O. The effects of sexual stimulation on the sexual performance of Hereford bulls. Journal of Animal Science, v.59, p.294-300, 1984.

NEVILLE JR., W.E.; WILLIAMS, D.J.;

RICHARDSON, K.L. et al. Relationship of breeding soundness evaluation score and its components with reproductive performance of beef bulls. Theriogenology, v.30, p.429-436, 1988.

OLIVEIRA, C.B.; GUIMARÃES, J.D.; COSTA, E.P. et al. Avaliação do comportamento sexual em touros Nelore: comparação entre os testes da libido em curral e do comportamento sexual a campo.

Revista Brasileira de Zootecnia, v.36, p.32-42, 2007.

PARVIZI, N. Neuroendocrine regulation of gonadotropins in the male and the female. Animal Reproduction Science, v.60, p.31-47, 2000.

PINCKARD, K.L.; STELLFLUG, J.; RESKO, J.A. et al. Review: brain aromatization and other factors affecting male reproductive behavior with emphasis on the sexual orientation of rams. Domestic Animal Endocrinology, v.18, p.83-96, 2000

PINEDA, N.; LEMOS, P.F.; FONSECA, V.O. Comparação entre dois testes de avaliação do comportamento sexual (libido) de touros Nelore (Bos taurus indicus). Revista Brasileira de Reprodução Animal, v.21, p.29-34, 1997.

PINTO, P.A.; SILVA, P.R.; ALBUQUERQUE, L.G. et al. Avaliação da biometria testicular e capacidade de monta em bovinos das raças Guzerá e Nelore. Revista Brasileira de Reprodução Animal, v.13, p.151-156, 1989.

QUIRINO, C.R.; BERGMANN, J.A.G.; VALE FILHO, V.R. et al. Genetic parameters of libido in Brazilian Nellore bulls. Theriogenology, v.62, p.1-7, 2004. 
RUPP, G.P.; BALL, L.; SHOOP, M.C. et al. Reproductive efficiency of bulls in natural service: effects of male to female ratio and single vs. multiple-sire breeding groups. Journal of the American Veterinary Medical Association, v.171, p.639-642, 1977.

SALVADOR, D.F. Perfis andrológico, de comportamento sexual e desempenho reprodutivo de touros Nelore desafiados com fêmeas em estro sincronizado. 2001. 53p. Dissertação (Mestrado em Medicina Veterinária) Escola de Veterinária, Universidade Federal de Minas Gerais, Belo Horizonte.

SALVADOR, D.F.; ANDRADE, V.J.; VALE FILHO, V.R. et al. Avaliação da libido de touros Nelore adultos em curral e sua associação com características andrológicas e desempenho reprodutivo a campo. Arquivo Brasileiro de Medicina Veterinária e Zootecnia, v.55, p.588593, 2003.

SAMPAIO, I. B. M. Estatística aplicada à experimentação animal. 2.ed. Belo Horizonte: FEP-MVZ, 2002. 265p.

SANTOS, N.R. Comportamento sexual de touros da raça Nelore (Bos taurus indicus) a pasto. 2001. 70p. Tese (Doutorado em Ciência Animal) Escola de Veterinária, Universidade Federal de Minas Gerais, Belo Horizonte.

SANTOS, M.D.; TORRES, C.A.A.; RUAS, J.R.M. et al. Teste da libido e atividade de monta em touros da raça Nelore. Arquivo Brasileiro de Medicina Veterinária e Zootecnia, v.56, p.504-510, 2004.

SAS. User's Guide. SAS Inst., Inc., Cary, NC. 1996.

SENGER, P.L. Pathways to pregnancy and parturition. 2.ed. Washington: Current Conceptions, Inc., 2003. 368p.
SILVA, E.V.C. Capacidade reprodutiva de touros Nelore: exame andrológico, teste de comportamento sexual e desafio de fertilidade. 1994. 102p. Dissertação (Mestrado em Medicina Veterinária) - Escola de Veterinária, Universidade Federal de Minas Gerais, Belo Horizonte.

TORRES JÚNIOR, J.R.S. Desenvolvimento ponderal e sexual de machos da raça Guzerá (Bos taurus indicus). 2004. 44p. Dissertação (Mestrado em Medicina Veterinária) - Escola de Veterinária, Universidade Federal de Minas Gerais, Belo Horizonte.

TROCÓNIZ, J.F.; BELTRÁN, J.; BASTIDAS, H. et al. Testicular development, body weight changes, puberty and semen traits of growing Guzerat and Nellore bulls. Theriogenology, v.35, p.815-826, 1991.

VALE FILHO, V.R. Padrões de sêmen bovino para o Brasil; análise e sugestões. In: CONGRESSO BRASILEIRO REPRODUÇÃO ANIMAL, 8, 1989, Belo Horizonte. Anais... Belo Horizonte: CBRA, 1989. V.2, p.94-118.

VALE FILHO, V. R., BERGMANN, J.A.G., ANDRADE, V.J. et al. Classificação andrológica por pontos (CAP), versus libido, na eficiência na fecundação de touros Nelore de 2 e 3 anos de idade, usados em estação de monta bem definida. In: Encontro de Pesquisa da Escola de Veterinária da UFMG, 14., Belo Horizonte. Anais... Belo Horizonte: UFMG, 1994. v.1, p.88.

ZUIN, L.F.S. Descrição e análise do comportamento sexual de touros da raça Nelore (Bos taurus indicus) aos dois e aos três anos de idade. 2000. 14p. Dissertação (Mestrado em Medicina Veterinária) - Escola de Veterinária. Universidade Federal de Minas Gerais, Belo Horizonte. 